\title{
Estimation of drying parameters including moisture diffusivity by using temperature measurements
}

\author{
G. H. Kanevce ${ }^{1}$, L. P. Kanevce ${ }^{2}$, V. B. Mitrevski ${ }^{2}$ \\ \& G. S. Dulikravich ${ }^{3}$ \\ ${ }^{I}$ Macedonian Academy of Sciences and Arts, Macedonia \\ ${ }^{2}$ Faculty of Technical Sciences,
}

St. Kliment Ohridski University, Macedonia

${ }^{3}$ Department of Mechanical and Materials Engineering, Florida

International University, USA

\begin{abstract}
This paper deals with the estimation of the moisture diffusivity, together with other thermophysical properties, as well as the heat and mass transfer coefficients of a convective drying body, on the basis of single thermocouple temperature measurements by using an inverse approach. Potato and apple slices have been chosen as representative drying bodies with significant shrinkage effects. A mathematical model of the drying process of shrinking bodies has been applied. The Levenberg-Marquardt method and a hybrid optimization method of minimization of a resulting least-squares norm were used to solve the present inverse problem. The experiments have been conducted on the experimental setup that is designed to simulate an industrial convective dryer. An analysis of the influence of the drying air speed, temperature and relative humidity, drying body dimensions, and drying time on the estimation of the unknown parameters enables the design of appropriate experiments that have been conducted as well. The estimated moisture diffusivities are compared with the results published by other authors. The experimental transient temperature and moisture content changes during the drying are compared with numerical solutions.
\end{abstract}

Keywords: inverse approach, thermophysical properties, drying. 


\section{Introduction}

An inverse approach to parameter estimation in the last few decades has become widely used in various scientific disciplines. In this paper, application of inverse concepts in drying is analyzed. A mathematical model of the drying process of shrinking bodies has been applied where the moisture content and temperature field in the drying body are expressed by a system of two coupled partial differential equations. The system of equations incorporates several coefficients that are functions of temperature and moisture content and must be determined experimentally. All the coefficients, except for the moisture diffusivity, can be relatively easily determined by experiments. The main problem in the moisture diffusivity determination by classical or inverse methods is the difficulty of moisture content measurements. We have recently analyzed a method for moisture diffusivity estimation by the temperature response of a drying body [16]. The main idea of this method is to make use of the interrelation between the heat and mass transport processes within the convective drying body and from its surface to the surroundings. Then, the moisture diffusivity, together with other thermophysical properties of the body, as well as the heat and mass transfer coefficients can be estimated on the basis of an accurate and easy to perform single thermocouple temperature measurement by using an inverse approach.

\section{A mathematical model of drying}

Drying of a single slice of thickness $2 L$ initially at uniform temperature and uniform moisture content is analysed in the paper, fig. 1. The surfaces of the drying body are in contact with the drying air. The problem is symmetrical relative to the mid-plane of the slice. The thickness of the body changes during the drying from $2 L_{0}$ to $2 L_{f}$.

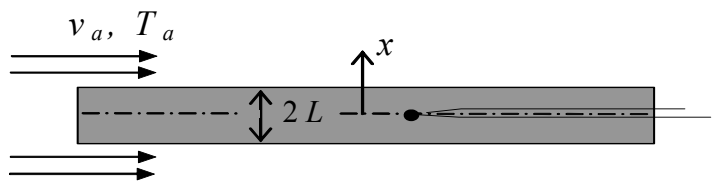

Figure 1: $\quad$ Scheme of the drying experiment.

In the case of an infinite flat plate the unsteady temperature, $T(x, t)$, and moisture content, $X(x, t)$, fields in the drying body are expressed by the following system of coupled nonlinear partial differential equations for energy and moisture transport

$$
c \rho_{s} \frac{\partial T}{\partial t}=\frac{\partial}{\partial x}\left(k \frac{\partial T}{\partial x}\right)+\varepsilon \Delta H \frac{\partial\left(\rho_{s} X\right)}{\partial t}
$$




$$
\frac{\partial\left(\rho_{s} X\right)}{\partial t}=\frac{\partial}{\partial x}\left(D \rho_{s} \frac{\partial X}{\partial x}\right)
$$

Here, $t, x, c, k, \Delta H, \varepsilon, D, \rho_{\mathrm{s}}$ are: time, normal distance from the mid-plane of the plate, specific heat, thermal conductivity, latent heat of vaporization, ratio of water evaporation rate to the reduction rate of the moisture content, moisture diffusivity, and density of dry solid, respectively.

The shrinkage effect of the drying body was incorporated through the changes of the specific volume of the drying body. There are several models for describing the changes of the specific volume of the body during drying. In this paper, linear relationship between the specific volume, $v_{s}$, and the moisture content, $X$, has been used

$$
v_{s}=\frac{1}{\rho_{s}}=\frac{V}{m_{s}}=\frac{1+\beta^{\prime} X}{\rho_{b 0}}
$$

where $m_{\mathrm{s}}$ is the mass of the dry material of the drying body, $V$ is the volume of the drying body, $\rho_{\mathrm{b} 0}$ is the density of a fully dried body and $\beta$ ' is the shrinkage coefficient.

The problem of the moving boundaries due to the changes of the dimensions of the body during the drying was resolved by introducing the dimensionless coordinate

$$
\psi=\frac{x}{L(t)}
$$

Substituting the above expression for $\rho_{\mathrm{s}}\left(=1 / v_{s}\right)$ and $\psi$ into eqns. (1) and (2) and rearranging, the resulting system of equations for the temperature and moisture content prediction becomes

$$
\begin{gathered}
\frac{\partial T}{\partial t}=\frac{k}{\rho_{s} c} \frac{1}{L^{2}} \frac{\partial^{2} T}{\partial \psi^{2}}+\frac{\psi}{L} \frac{d L}{d t} \frac{\partial T}{\partial \psi}+\frac{\varepsilon \Delta H}{c} \frac{\rho_{s}}{\rho_{b 0}}\left(\frac{\partial X}{\partial t}-\frac{\psi}{L} \frac{d L}{d t} \frac{\partial X}{\partial \psi}\right) \\
\frac{\partial X}{\partial t}=D \frac{\rho_{b 0}}{\rho_{s}} \frac{1}{L^{2}} \frac{\partial^{2} X}{\partial \psi^{2}}+\left[\frac{\rho_{b 0}}{\rho_{s}^{2}} \frac{1}{L^{2}} \frac{\partial\left(D \rho_{s}\right)}{\partial \psi}+\frac{\psi}{L} \frac{d L}{d t}\right] \frac{\partial X}{\partial \psi}
\end{gathered}
$$

The initial conditions are

$$
t=0: \quad T(\psi, 0)=T_{0}, X(\psi, 0)=X_{0} .
$$

The temperature and the moisture content boundary conditions on the surfaces of the drying body in contact with the drying air are 


$$
\begin{gathered}
-k \frac{1}{L}\left(\frac{\partial T}{\partial \psi}\right)_{\psi=1}+j_{q}-\Delta H(1-\varepsilon) j_{m}=0 \\
D \rho_{s} \frac{1}{L}\left(\frac{\partial X}{\partial \psi}\right)_{\psi=1}+j_{m}=0
\end{gathered}
$$

The convective heat flux, $j_{q}(t)$, and mass flux, $j_{m}(t)$, on these surfaces are

$$
\begin{gathered}
j_{q}=h\left(T_{a}-T_{\psi=1}\right) \\
j_{m}=h_{D}\left(C_{\psi=1}-C_{a}\right)
\end{gathered}
$$

where $h$ is the heat transfer coefficient, and $h_{D}$ is the mass transfer coefficient, $T_{a}$ is the temperature of the drying air, and $T_{\psi=1}$ is the temperature on the surfaces of the drying body.

The water vapour concentration in the drying air, $C_{a}$, is calculated from

$$
C_{a}=\frac{\varphi p_{s}\left(T_{a}\right)}{R_{w} T_{k, a}}
$$

where $\varphi$ is the relative humidity of the drying air and $p_{s}$ is the saturation pressure. The water vapor concentration of the air in equilibrium with the surface of the body exposed to convection is calculated from

$$
C_{\psi=1}=\frac{a\left(T_{\psi=1}, X_{\psi=1}\right) p_{s}\left(T_{\psi=1}\right)}{R_{w} T_{k, \psi=1}}
$$

The water activity, $a$, or the equilibrium relative humidity of the air in contact with the convection surface at temperature $T_{\psi=1}$ and moisture content $X_{\psi=1}$ are calculated from experimental water sorption isotherms.

The boundary conditions on the mid-plane of the drying slice are

$$
\left(\frac{\partial T}{\partial \psi}\right)_{\psi=0}=0, \quad\left(\frac{\partial X}{\partial \psi}\right)_{\psi=0}=0 .
$$

Problem defined by eqns. (5)-(12) is referred to as a direct problem when initial and boundary conditions as well as all the parameters appearing in the formulation are known. The objective of the direct problem is to determine the temperature and moisture content fields in the drying body.

In order to approximate the solution of eqns. (5) and (6), an explicit numerical procedure has been used. 


\section{Inverse approach}

For the inverse problem of interest here, the thermophysical properties and the boundary conditions parameters of a drying body are regarded as unknown parameters.

The estimation methodology used is based on the minimization of the ordinary least square norm

$$
E(\mathbf{P})=[\mathbf{Y}-\mathbf{T}(\mathbf{P})]^{\mathrm{T}}[\mathbf{Y}-\mathbf{T}(\mathbf{P})]
$$

Here, $\mathbf{Y}^{\mathrm{T}}=\left[Y_{1}, Y_{2}, \ldots, Y_{\text {imax }}\right]$ is the vector of measured temperatures, $\mathbf{T}^{\mathrm{T}}=\left[T_{1}(\mathbf{P})\right.$, $\left.T_{2}(\mathbf{P}), \ldots T_{\max }(\mathbf{P})\right]$ is the vector of estimated temperatures at time $t_{\mathrm{i}}(\mathrm{i}=1,2, \ldots$, imax), $\mathbf{P}^{\mathrm{T}}=\left[P_{1}, P_{2}, \ldots P_{\mathrm{N}}\right]$ is the vector of unknown parameters, imax is the total number of measurements, and $\mathrm{N}$ is the total number of unknown parameters $(\operatorname{imax} \geq \mathrm{N})$.

A hybrid optimization algorithm OPTRAN [7] and the Levenberg-Marquardt method [8] have been utilized for the minimization of $E(\mathbf{P})$ representing the solution of the present parameter estimation problem.

The Levenberg-Marquardt method is a stable and straightforward gradient search minimization algorithm that has been applied to a variety of inverse problems. It belongs to a general class of damped least squares methods.

An alternative to the Levenberg-Marquardt algorithm, especially when searching for a global optimum of a function with possible multiple minima, is the hybrid optimization program OPTRAN. OPTRAN incorporates six of the most popular optimization algorithms: the Davidon-Fletcher-Powell gradient search, sequential quadratic programming algorithm, Pshenichny-Danilin quasiNewtonian algorithm, a modified Nelder-Mead simplex algorithm, a genetic algorithm, and a differential evolution algorithm. Each algorithm provides a unique approach to optimization with varying degrees of convergence, reliability and robustness at different stages during the iterative optimization procedure. The hybrid optimizer OPTRAN includes a set of rules and switching criteria to automatically switch back and forth among the different algorithms as the iterative process proceeds in order to avoid local minima and accelerate convergence towards a global minimum.

\section{Experimental}

Real experiments have been conducted to investigate the applicability of the method to food processing, when involving drying of thin flat samples. The experiments have been conducted on the experimental setup that is designed to simulate an industrial convective dryer.

Drying of approximately three millimeter thick potato or apple slices have been examined. The slices have been in contact with the drying air from the top and the bottom surfaces. Two shelves, fig. 2, each holding three moist slices 


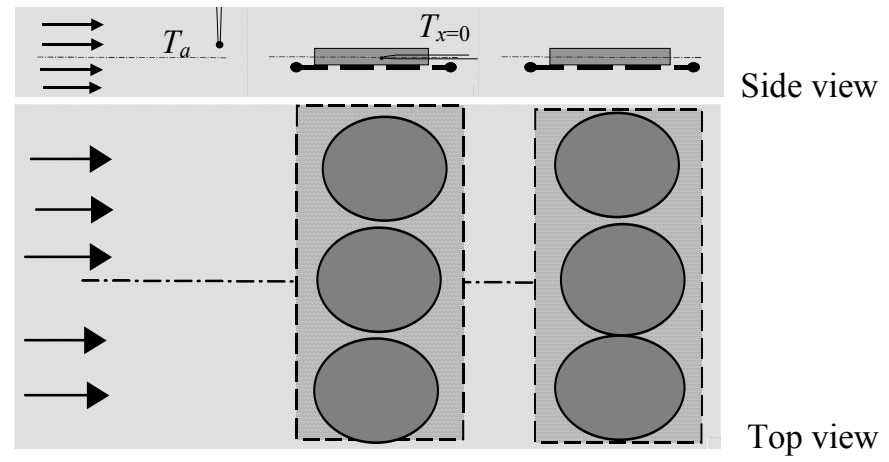

Figure 2: Scheme of the experimental setup.

have been introduced into the rectangular experimental channel of dimensions 25 x $200 \mathrm{~mm}$.

A micro-thermocouple was inserted in the midplane of each of the three slices on the first shelf. An arithmetical mean of the readings from the three thermocouples was used as a transient temperature reading, for the estimation of the unknown parameters. The slices on the second shelf were weighed every ten minutes in order to obtain the volume-averaged moisture content change during drying. The temperature of the drying air, $\mathrm{T}_{\mathrm{a}}$, has been recorded as well. The initial moisture content, $\mathrm{X}_{0}$, and the initial slices thickness, $2 \mathrm{~L}_{0}$, were measured for each of the experiments.

The experiments were designed by using the so-called D-optimum criterion. From the relative sensitivity coefficients analysis, the drying air velocity, drying air temperature and drying body dimension were defined. Determinant of the information matrix with normalized elements has been calculated in order to define drying time. The duration of the drying experiment corresponding to the maximum determinant value was used.

A number of drying experiments with similar experimental conditions, $\left(T_{a}=\right.$ $56.6-59.5^{\circ} \mathrm{C}, 2 L_{0}=2.36-3.14 \mathrm{~mm}, X_{0}=3.70-4.83 \mathrm{~kg} / \mathrm{kg}$ and $T_{0}=14.9-17.7^{\circ} \mathrm{C}$ ), have been carried out.

\section{Results and discussion}

In this paper, application of the proposed method for simultaneous estimation of the moisture diffusivity, together with other thermophysical properties of vegetables and fruits, as well as the heat and mass transfer coefficients has been analyzed.

From the conducted sensitivity coefficients analysis it was concluded that in the convective drying experiment it is possible, based on a single thermocouple temperature response, to estimate simultaneously the moisture diffusivity, the convection heat and mass transfer coefficients, and the relative humidity of the 
drying air. All other quantities appearing in the direct problem formulation were taken from published data of other authors.

Moisture diffusivity of foods is very often considered as an Arrhenius-type temperature function $[9,10]$

$$
D=D_{0} \exp \left[-E_{0} /\left(R T_{k}\right)\right]
$$

with constant values of the Arrhenius factor, $D_{0}$, and the activation energy for moisture diffusion, $E_{0}$.

Table 1 shows the computationally obtained parameters and RMS-error for potato, for experiment P1: $T_{a}=58.13{ }^{\mathrm{O}} \mathrm{C}, 2 L_{0}=3.14 \mathrm{~mm}, X_{0}=4.80 \mathrm{~kg} / \mathrm{kg}$ and $T_{0}$ $=17.53{ }^{\mathrm{O}} \mathrm{C}$ and for apple, for experiment A1: $T_{a}=60.17{ }^{\mathrm{O}} \mathrm{C}, 2 L_{0}=2.96 \mathrm{~mm}, X_{0}$ $=6.46 \mathrm{~kg} / \mathrm{kg}$ and $T_{0}=16.91{ }^{\mathrm{O}} \mathrm{C}$.

In fig. 3 the estimated moisture diffusivities are compared with the results published by other authors [11].

In fig. 4 the experimental transient temperature reading, $T_{x=0}$, and the experimental volume-averaged moisture content change during drying of potato are compared with numerical solutions for the estimated parameters. A similar, very good agreement was obtained for apple slice as well.

Table 1: $\quad$ Estimated parameters and RMS-error.

\begin{tabular}{|c|c|c|}
\hline & Potato & Apple \\
\hline$D_{0} \cdot 10^{3}\left[\mathrm{~m}^{2} \mathrm{~s}^{-1}\right]$ & 7.985 & 63.905 \\
\hline$E_{0}\left[\mathrm{~kJ} \mathrm{~mol}^{-1}\right]$ & 43.3 & 50.215 \\
\hline$h\left[\mathrm{~W} \mathrm{~m}^{-2} \mathrm{~K}^{-1}\right]$ & 31.08 & 24.137 \\
\hline$h_{D} \cdot 10^{2}\left[\mathrm{~m} \mathrm{~s}^{-1}\right]$ & 3.48 & 2.70 \\
\hline$\varphi[-]$ & 0.0899 & 0.1011 \\
\hline$R M S\left[{ }^{\mathrm{O}} \mathrm{C}\right]$ & 0.55 & 0.64 \\
\hline
\end{tabular}
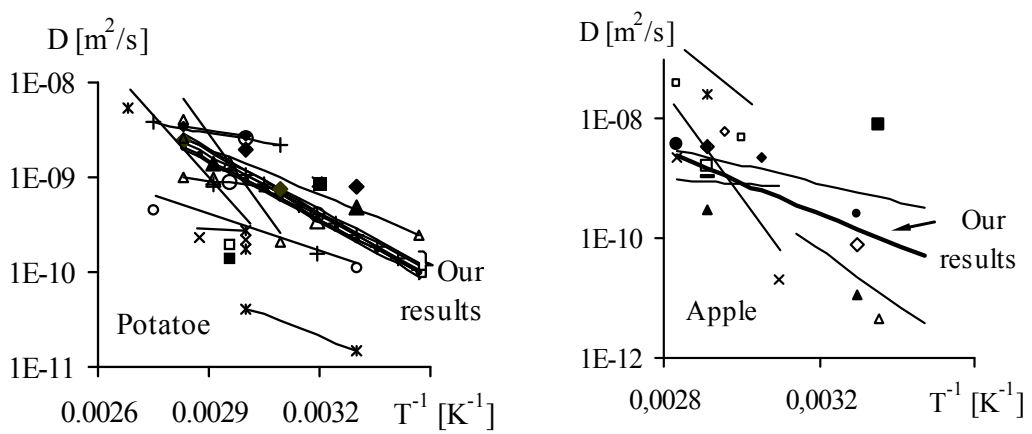

Figure 3: $\quad$ Moisture diffusivity of potatoes and apples. 


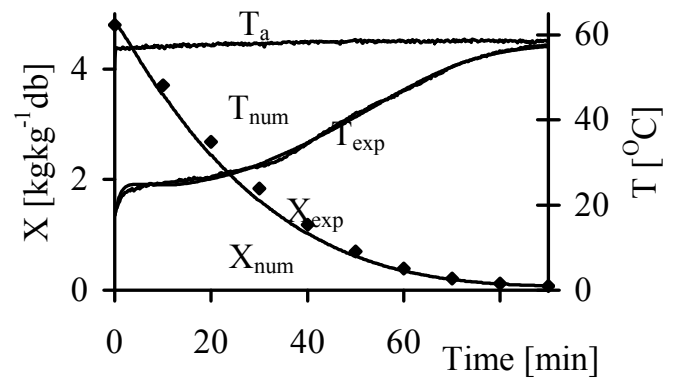

Figure 4: The mid-plane temperature, $\mathrm{T}$, the temperature of the drying air, $\mathrm{T}_{\mathrm{a}}$, and the volume-averaged moisture content, $\mathrm{X}$, changes during the drying of a potato slice.

\section{Conclusions}

It can be concluded that in the convective drying experiments of apples and potatoes it is possible, based on a single thermocouple temperature response, to estimate simultaneously the moisture diffusivity, the convection heat and mass transfer coefficients, and the relative humidity of the drying air.

Estimated moisture diffusivities compare well with the values obtained by other authors who utilized different methods.

Very good agreement between the experimental and numerical temperature and volume-averaged moisture content changes during drying has been obtained.

\section{References}

[1] Kanevce, G.H. Kanevce, L.P. \& Dulikravich, G.S., Moisture diffusivity estimation by temperature response of a drying body, Proc. of the $2^{\text {nd }}$ Int. Conf. On Inverse Problems in Engineering Mechanics, eds. M. Tanaka \& G. S. Dulikravich, Elsevier: Amsterdam, pp. 43-52, 2000.

[2] Kanevce, G.H. Kanevce, L.P. \& Dulikravich, G.S., An inverse method for drying at high mass transfer Biot number, Proc. of the HT03 ASME Summer Heat Transfer Conference, Las Vegas, Nevada, USA, ASME paper HT20003-40146, 2003.

[3] Kanevce, G.H. Kanevce, L.P., Dulikravich, G.S., \& Orlande, H.R.B., Estimation of thermophysical properties of moist materials under different drying conditions, Inverse Problems in Science and Engineering, 13(4), pp. 341-354, 2005.

[4] Kanevce, G.H. Kanevce, L.P., \& Dulikravich, G.S., Application of inverse concepts to drying, Thermal Science, 9(2), pp. 31-44, 2005. 
[5] Kanevce, G.H. Kanevce, L.P., Mitrevski, V.B., Dulikravich, G.S., \& Orlande, H.R.B., Inverse approaches to drying with and without shrinkage, Proc. of the $15^{\text {th }}$ Int. Drying Symposium (IDS'2006), ed. I. Farkas, Budapest, Hungary, Vol. A, p. 576, 2006.

[6] Kanevce, G.H. Kanevce, L.P., Mitrevski, V.B., Dulikravich, G.S., \& Orlande, H.R.B., Inverse approaches to drying of thin bodies with significant shrinkage effects, Journal of Heat Transfer, 129(3), pp. 379386, 2007.

[7] Dulikravich, G.S., Martin, T.J., Dennis, B.H. \& Foster, N.F. Multidisciplinary hybrid constrained GA optimization, Evolutionary Algorithms in Engineering and Computer Science: Recent Advances and Industrial Applications (EUROGEN'99), eds. K. Miettinen, M. M. Makela, P. Neittaanmaki \& J. Periaux, John Wiley \& Sons, Ltd., Jyvaskyla, Finland, pp. 231-260, 1999.

[8] Marquardt, D.W., An algorithm for least squares estimation of nonlinear parameters, J. Soc. Ind. Appl. Math., 11, pp. 431-441, 1963.

[9] Rovedo, C., Suarez C. \& Viollaz P., Analysis of moisture profiles, mass Biot number and driving forces during drying of potato slabs, J. of Food Engineering, 36, pp. 211-231, 1998.

[10] Zogzas N.P. \& Maroulis Z.B., Effective moisture diffusivity estimation from drying data: A comparison between various methods of analysis, Drying Technology, 14(7\&8), pp. 1543-1573, 1996.

[11] Mitrevski, V.B., Investigation of the drying processes by inverse methods, PhD. Thesis, University of Bitola, Macedonia, 2005 